\title{
FOOD INTAKE, FOOD PURCHASING ACCESS, AND STRESS DURING THE COVID-19 PANDEMIC: A DESCRIPTIVE STUDY AMONG COLLEGE STUDENTS OF JENDERAL SOEDIRMAN UNIVERSITY
}

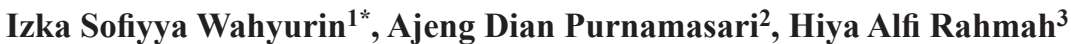 \\ ${ }^{1,3}$ Nutrition Sciences, Jenderal Soedirman University, Purwokerto, Indonesia \\ ${ }^{2}$ Sport Sciences, Jenderal Soedirman University, Purwokerto, Indonesia \\ *E-mail: izka.sofiyya.wahyurin@unsoed.ac.id
}

\begin{abstract}
The COVID-19 pandemic is causing social restrictions that leads to school form home. Long period of online learning system will likely make excessive food intakes and adolescent would try popular diet, got high stress due to staying at home for a long period of time, and decreased of food purchasing access. This study aimed to describe the food intakes, food purchasing access, and stress level among college students of Jenderal Soedirman University during pandemic period. This study was crossectional design study with data collection using purposive sampling. Total samples were 361 students from Jenderal Soedirman University Students. Descriptive Analytical data was shown using percentage, mean, and standard deviation. Food intake data was collected using 24 hours food recall and food purchasing access was determined by the online questionnaire with question about how the respondents get the access to buy food during pandemic Energy intakes, macro nutrients, vitamins C and vitamins A of Jenderal Soedirman University Students during pandemic era were inadequate compared to their nutritional needs. Most of the students feel stressed during pandemic because they were worried they might get infected by COVID-19 either themselves or their family.
\end{abstract}

Keywords: COVID-19, food intake, food purchasing access, stress, college students

\section{INTRODUCTION}

Year of 2020 became a very different and challenging year in all around the world because of the Coronavirus Disease 2019 (COVID-19) that has been evoluted from an isolated disease in Wuhan City, China (AMJC, 2020). Indonesia has reported that the first positive case confirmed was on March $2^{\text {nd }} 2020$ and then transpasses from person to person. On March $11^{\text {th }} 2020$, World Health Organization (WHO) declared that COVID-19 is a world pandemic disease. In order to decrease the number of the case, Indonesian government has stated social restrictions in several cities and it was being extended because the case is still increasing, in February $14^{\text {th }}$ 2021, there was 6765 positive COVID-19 cases confirmed and as a result Indonesia has reached 1.217 .468 positive COVID-19 cases (UNICEF et al., 2020).

Social restrictions can impact daily routines and life style such as food purchasing access and food consumptions, outdoor activities, traveling, education and sport activities (Hossain et al., 2020). The effects of the social restrictions implicated the eating ability becomes off-schedule and the consumption of snacks could affect high calories intakes (Scully et al., 2019). The changes that have occurred during the COVID-19 pandemic are related to feelings of fear, anxiety, and stress experienced by large part of society (Anton \& Miller, 2015).

In the middle of March 2020, hundred millions of students especially young adults had to face schools being closed down or experiencing learning from home (Xiang et al., 2020). The implementations of social restrictions and schools close down with unknown period of time will have long term effects on young adults' well being. Previous study has shown that students who don't go to school such as during weekends and long holiday would likely has excessive food intake and tried popular diet for adolescents that could affect on the increasing of body weight (Brazendale et al., 2017; Lin et al., 2018).

Pandemic era has made most of people limits their activities outside their house, one of them was food and food ingredients purchases. Most of individuals would buy food ingredients in the store when they need to buy fruits $(80.1 \%)$ and 
vegetables (77.2\%) (Zhao et al., 2020). This study has shown that every new confirmed COVID19 cases would increase online sales up to $5.7 \%$ and the amount of new customers increased $4.9 \%$ (Chang \& Meyerhoefer, 2020), and during the lockdown, online food delivery has increased $9 \%$ (Di Renzo et al., 2020). The types of food items that were mostly purchased during the lockdown period were energy-dense foods and processed foods with many stages or ultra-processed foods such as sausages and corned beef.

Based on the above backgrounds and the lack of research literature examined in Indonesia, in this study, researchers examined food intake, food purchasing access and stress during the COVID-19 pandemic among students of Jenderal Soedirman University.

\section{METHODS}

This study used an observational analytic research design with a cross-sectional design study. The population in this study were college students of Jenderal Soedirman University who were doing study from home because of COVID19 Pandemic. Data collections were conducted on June $10^{\text {th }}$ to $22^{\text {nd }} 2020$. Respondents were selected by purposive sampling with total of 361 students as respondents.

The data was collected using questionnaire through google form in order to limit from physical meeting with the respondents during COVID19 pandemic. Questionnaire was used to asses behaviour such as food intakes, food access and stress during social restriction in students of Jenderal Soedirman University. Food intake data was collected using 24 hours food recall with phone call to determine portion size and then the data was processed using Nutrisurvey in order to calculate the quantity of food intake and they were grouped by the food item ingredients which mostly consumed during pandemic. Food purchasing access was determined by the online questionnaire with question about how the respondents get the access to buy food during pandemic. The stress data experienced by respondents were determined based on a questionnaire with questions about feeling of fear during lockdown as well as respondents' concerns about being exposed to the COVID-19.
Data analysis that used was in percentage form and mean in each variables. This data was analyzed using SPSS software version 23. This study has been approved by the Ethics Committee of the faculty of health sciences Jenderal Soedirman University number 0105/EC/KEPEK/VI/2020.

\section{RESULT AND DISCUSSION}

The characteristics of respondents in this study were shown in Table 1. Most of the respondents were in the age range of $\geq 21$ years old and have normal nutritional status.

The average nutritional intake of students during the pandemic was shown in Table 2. The average nutritional intake of the respondents was $1109.3 \mathrm{kcal}$, compared to the 2018 Recommended Dietary Allowance (RDA) Indonesia for males, which was $2650 \mathrm{kcal}$ and $2100 \mathrm{kcal}$ for females aged 16-18 years old. Based on these data mentioned, most of the respondents only meet $41.8-52.8 \%$ of their energy needs per day. The average of respondents' carbohydrate intake was $128 \mathrm{~g}$ and compared to the $2018 \mathrm{RDA}$ Indonesia, most of respondents only meet $32-42.7 \%$ of their carbohydrates need per day. Inadequate food intake may occur due to limited access to adequate and nutritious food. Limited access to food for students is caused by social restrictions and job losses during the COVID-19 pandemic. Some students reported travel restrictions in residential areas so they were more likely to experience food insecurity (Payne et al., 2018). In addition, the possibility of losing a job at a part-time student job or a parent's main job is a factor in food insecurity (Wolfson, 2020).

Inadequate intake of macro nutrients in respondents could happen due to family's financial

Table 1. The Characteristics of Respondents

\begin{tabular}{lc}
\hline \multicolumn{1}{c}{ Variable } & $\mathbf{n}(\mathbf{\%})$ \\
\hline Age & $60(16.6)$ \\
$<21$ years old & $301(83.4)$ \\
$\geq 21$ years old & \\
Nutritional Status & $290(80.3)$ \\
$\quad$ Normal & $26(7.2)$ \\
Overweight & $45(12.5)$ \\
Obesity & $22.2 \pm 4,1$ \\
Nutritional Status $\left(\mathbf{k g} / \mathbf{m}^{\mathbf{2}}\right)$ &
\end{tabular}


situation. Previous studies have shown that during adolescents, the family financial situation worsened during the pandemic, which had an impact on their intakes (Allabadi et al., 2020). The effect of low energy intake for a certain period of time will cause a decrease in nutritional status and if the energy intake is balanced it will help to maintain normal nutritional status (Indartanti \& Kartini, 2014).

Thus adequate intake of vitamin A was one of the ways to prevent infection of the lungs in COVID-19 cases (Michele et al., 2020). In addition, vitamin $\mathrm{E}$ intake can improve immune function and affect the host, one of them is such as reducing the risk of viral infection (Michele et al., 2020). Meanwhile the vitamin $C$ intake can prevent susceptibility to lower respiratory tract infections under certain conditions such as improvement of lung inflammation (Michele et al., 2020). The respondents' average intake of Vitamins $\mathrm{E}$ and $\mathrm{C}$ was $3.5 \mathrm{mcg}$ dan $45.7 \mathrm{mg}$ and compared to the 2018 RDA, the respondents only meet $23 \%$ and $50.8 \%$ of their needs. Vitamins intake in this study was not yet included with their consumption of multivitamin supplements. However, in case of vitamin A intake, the average intake was $877 \mathrm{RE}$ or $134 \%$ sufficient.

During this pandemic period, $26.9 \%$ respondents tend to consume instant foods and snacks such as instant noodles, sweet biscuits or high calories street foods, those will be shown in Table 2. Respondents often consume instant meals and snacks due to ease of processing due to limited sources of fresh food during social restrictions. Previous study has shown that 7,1\% of the respondents chose to not consume healthy foods during the lockdown period because they faced various temptations to eat instant foods and get bored easily when they were at home. Other study shown that there was $17,7 \%$ of the respondents who chose to buy foods with long shelf life, $11,1 \%$ frozen foods, and 3,1\% chose instant foods (Poelman et al., 2021).

Vegetables and fruits intake has shown very interesting results in this study. Based on Table 2, during this pandemic period, $23.5 \%$ of students chose vegetables and fruits to be consumed, to meet their vitamin and mineral needs. This was also confirmed by previous research, in which
Table 2. College Students' Intake during Pandemic Period

\begin{tabular}{lc}
\hline \multicolumn{1}{c}{ Variable } & n (SD) \\
\hline Energy (kcal) & $1109.3(407.7)$ \\
Carbohydrates (g) & $128.0(54.4)$ \\
Protein (g) & $43.3(19.8)$ \\
Fat (g) & $51.4(24.1)$ \\
Vitamin A (RE) & $877.9(921.5)$ \\
Vitamin E (mcg) & $3.5(2.3)$ \\
Vitamin C (mg) & $45.7(54.6)$ \\
Food Types (n(\%)) & \\
$\quad$ Rice & $50(16.6)$ \\
$\quad$ Animal Proteins & $94(26)$ \\
Vegetable Proteins & $25(6.9)$ \\
Vegetables \& Fruits & $85(23.5)$ \\
$\quad$ Instant foods \& snacks & $97(26.9)$ \\
\hline
\end{tabular}

$9.6 \%$ of people tended to choose healthier foods during the lockdown because they thought the need for micronutrients was increasing in order to maintain our immune system (Poelman et al., 2021).

Food purchasing access during pandemic become something that needs to be addressed due to the limited access for people to get daily needs. In the time of lockdown period, most of the students were in their house and the foods they consumes were home cooking foods $(48,2 \%)$, which can be seen in Table 3. The previous study shown that $30,3 \%$ of the family has extra time to prepare meal for their family during pandemic (Poelman et al., 2021).

Buying cooked foods during pandemic using a delivery order service became the second most common choice (29.9\%), based on Table 3. Social distancing allows people to have limited interaction with the social people residing at home and have a limited chance to spread the coronavirus, among others. Social isolation or distancing can lead to food delivery, as delivery services provide a way of bonding socially while being physically isolated (Sukumaran, 2020). During the lockdown period, $29.5 \%$ of respondents used food delivery services more often than before the lockdown period (Poelman et al., 2021).

The COVID-19 pandemic has an impact on several students' mental health. This pandemic raises new stresses such as feeling of fear and worry of themselves and loved ones, boredom 
Table 3. Food Access and Purchases of the Students during Pandemic

\begin{tabular}{lc}
\hline \multicolumn{1}{c}{ Variable } & n (\%) \\
\hline Food Access and Purchases & \\
Cooked by parents or other family member & $174(48.2)$ \\
Self cooking & $78(21.6)$ \\
Buys cooked foods & $108(29.9)$ \\
\hline
\end{tabular}

Table 4. College Students' Stress during Pandemic

\begin{tabular}{lc}
\hline \multicolumn{1}{c}{ Variable } & n (\%) \\
\hline Boredom during lockdown & $303(83.9)$ \\
Yes & $58(16.1)$ \\
No & \\
Started to Feel Boredom & $65(18.0)$ \\
Didn't Give Answer & $78(21.6)$ \\
In The First 1 week & $110(30.5)$ \\
In The First 1 month & $81(22.4)$ \\
In The First 2 months & $27(7.5)$ \\
In The First 3 months & \\
Activities when feeling bored & $58(16.1)$ \\
Didn't Give Answer & $216(59.8)$ \\
Entertains & $28(7.8)$ \\
Sports & $43(11.9)$ \\
Doing Chores & $16(4.4)$ \\
Lecture Tasks & \\
Follow News Update about COVID-19 & \\
Yes & $340(90.2)$ \\
No & $21(5.8)$ \\
Source of COVID-19 News Update & \\
Didn't Know & $15(4.4)$ \\
Social Media & $2799(77.3)$ \\
Electronic News & $3(0.8)$ \\
Television & $63(17.5)$ \\
Anxious Over COVID-19 & \\
Yes & $295(81.7)$ \\
No & $66(18.3)$ \\
\hline
\end{tabular}

at home during the lockdown period and sudden changes in lifestyle (Xie et al., 2020). Some respondents felt bored at home $(83.9 \%)$ and boredom began to be felt in the first one month of the lockdown period (30.5\%), which were listed in Table 4. Activities that were often carried out during the quarantine period were doing some entertaining activities $(59.8 \%)$, such as watching movies, playing games, and other screen time activities. Previous research reported that $45 \%$ of adolescents did not do physical activity (such as walking, running, or doing housework) during the pandemic, they spent more time on watching television and using gadgets during the pandemic compared to before the pandemic period (Allabadi et al., 2020). Tractions such as social media, internet, video, and games have reduced the concentration of students in receiving learning during the pandemic (Son et al., 2020).

During the pandemic period, $90.2 \%$ of students followed the news of COVID-19, such as the number of new cases and deaths. Most of the students saw these news through social media $(77.3 \%)$. This news caused the majority of students or $81.7 \%$ to be very anxious about this contagious disease (Table 4). Previous research also found that $43 \%$ of respondents were worried about the wellbeing of themselves and their loved ones, especially in more vulnerable groups such as parents, grandparents and nephews who are still under five. In addition, severe anxiety was also found when students experienced a slight cough or other signs of COVID-19, they felt worried about being exposed to COVID-19 (Son et al., 2020).

\section{CONCLUSIONS}

Energy intake, macro nutrient, and vitamins $\mathrm{C}$ and $\mathrm{A}$ for students of Jenderal Soedirman University during the pandemic did not meet the recommended nutritional needs. During the pandemic, students eat by getting food from their parents or family. Most students feel stressed during this pandemic because they were worried that they might get exposed to COVID-19 either both themselves or their family.

Furthermore, the university and students themselves must be able to prevent the negative impact of COVID-19 which affects intake and stress on students. Sufficient macro and micronutrient intake, clean and safe food sources, and prevention of stress in students can be developed by the university through using virtual spaces and telemedicine programs to promote nutritional programs. Future research is expected to examine the differences before and during this pandemic period on food intake, weight gain, and changes in hygiene and sanitation patterns in college students. 


\section{ACKNOWLEDGEMENTS}

This research was funded by Research Institutions and Community Service, Jenderal Soedirman University.

\section{REFERENCES}

AMJC. (2020). A timeline of COVID-19 developments in 2020. Retrieved from https:// www.ajmc.com/view/a-timeline-of-covid19developments-in-2020

Anton, S. D., \& Miller, P. M. (2015). Do negative emotions predict alcohol consumption, saturated fat intake, and physical activity in older adults? Behavior Modification, 29(4), 677-688. doi: 10.1177/0145445503261164

Brazendale, K., Beets, M. W., Weaver, R. G., Pate, R. R., Turner-McGrievy, G. M., Kaczynski, A. T., Chandler, J. L., Bohnert, A., \& von Hippel, P. T. (2017). Understanding differences between summer vs. school obesogenic behaviors of children: the structured days hypothesis. International Journal of Behavioral Nutrition and Physical Activity, 14(1), 1-14. doi: 10.1186/ s12966-017-0555-2

Chang, H., \& Meyerhoefer, C. D. (2020). COVID-19 and the Demand for Online Food Shopping Services: Empirical Evidence from Taiwan. American Journal of Agricultural Economics, 103(2), 448-465. doi: 10.1111/ajae. 12170

Di Renzo, L., Gualtieri, P., Pivari, F., Soldati, L., Attinà, A., Cinelli, G., Leggeri, C., Caparello, G., Barrea, L., \& Scerbo, F. (2020). Eating habits and lifestyle changes during COVID19 lockdown: an Italian survey. Journal of Translational Medicine, 18,1-15. doi: 10.1186/ s12967-020-02399-5.

Hossain, M. M., Sultana, A., \& Purohit, N. (2020). Mental health outcomes of quarantine and isolation for infection prevention: a systematic umbrella review of the global evidence. Epidemiology Health, 42, 1-11. doi: 10.4178/ epih.e2020038

Indartanti, D., \& Kartini, A. (2014). Hubungan status gizi dengan kejadian anemia pada remaja putri. Journal of Nutrition College, 3(2), 310316. doi: 10.14710/jnc.v3i2.5438

Lin, Y., Tremblay, M. S., Katzmarzyk, P. T., Fogelholm, M., Hu, G., Lambert, E. V, Maher, C., Maia, J., Olds, T., \& Sarmiento, O. L. (2018). Temporal and bi-directional associations between sleep duration and physical activity/ sedentary time in children: An international comparison. Preventive Medicine, 111, 436441. doi: 10.1016/j.ypmed.2017.12.006

Michele, C. A., Angel, B., Valeria, L., Teresa, M., Giuseppe, C., Giovanni, M., Ernestina, P., \& Mario, B. (2020). Vitamin supplements in the Era of SARS-Cov2 pandemic. GSC Biological and Pharmaceutical Sciences, 11(2), 7-19. doi: 10.30574/gscbps.2020.11.2.0114

Payne-Sturges, D. C., Tjaden, A., Caldeira, K. M., Vincent, K. B., \& Arria, A. M. (2018). Student hunger on campus: Food insecurity among college students and implications for academic institutions. American Journal of Health Promotion, 32(2), 349-354. doi: doi. org/10.1177/0890117117719620

Poelman, M. P., Gillebaart, M., Schlinkert, C., Dijkstra, S. C., Derksen, E., Mensink, F., Hermans, R. C. J., Aardening, P., de Ridder, D., $\&$ de Vet, E. (2021). Eating behavior and food purchases during the COVID-19 lockdown: A cross-sectional study among adults in the Netherlands. Appetite, 157, 105002. doi: 10.1016/j.appet.2020.105002

Scully, M., Dixon, H., \& Wakefield, M. (2019). Association between commercial television exposure and fast-food consumption among adults. Public Health Nutrition, 12(1), 105-110. doi : $10.1017 / \mathrm{S} 1368980008002012$

Son, C., Hegde, S., Smith, A., Wang, X., \& Sasangohar, F. (2020). Effects of COVID-19 on college students' mental health in the United States: Interview survey study. Journal of Medical Internet Research, 22(9), e21279. doi: $10.2196 / 21279$

Sukumaran, T. (2020). Coronavirus: Malaysia warns of "tsunami-like" third wave of infections if lockdown not respected. This Week in Asia. Retrieved from https://www.scmp.com/weekasia/economics/article/3075778/malaysiascoronavirus-lockdown-confusion-uncertaintyand-some

UNICEF, WHO, \& World Bank. (2020). Levels and trends in child malnutrition: Key findings of the 2020 Edition of the Joint Child Malnutrition Estimates. In $W H O, 24(2)$. Retrieved from https://www.who.int/publications/i/item/jme2020-edition

Wolfson, J. A., \& Leung, C. W. (2020). Food insecurity and COVID-19: Disparities in early effects for US adults. Nutrients, 12(6), 1648. doi: 10.3390/nu12061648

Xiang, M., Zhang, Z., \& Kuwahara, K. (2020). Impact of COVID-19 pandemic on children 
and adolescents' lifestyle behavior larger than expected. Progress in cardiovascular diseases, 63(4), 531-532. doi: 10.1016/j. pcad.2020.04.013

Xie, X., Xue, Q., Zhou, Y., Zhu, K., Liu, Q., Zhang, J., \& Song, R. (2020). Mental health status among children in home confinement during the coronavirus disease 2019 outbreak in Hubei Province, China. JAMA Pediatrics, 174(9), 898900. doi: 10.1001/jamapediatrics.2020.1619 Zhao, A., Li, Z., Ke, Y., Huo, S., Ma, Y., Zhang, Y., Zhang, J., \& Ren, Z. (2020). Dietary diversity among Chinese residents during the COVID-19 outbreak and its associated factors. Nutrients, 12(6), 1699. doi: /10.3390/nu12061699 